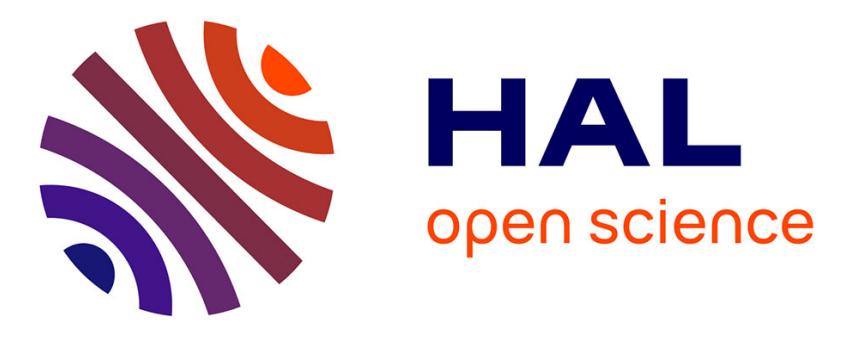

\title{
Picosecond pulsed laser for microscale sample preparation
}

\author{
Antoine Guitton, A. Irastorza-Landa, R. Broennimann, D. Grolimund, S. van \\ Petegem, H. van Swygenhoven
}

\section{- To cite this version:}

Antoine Guitton, A. Irastorza-Landa, R. Broennimann, D. Grolimund, S. van Petegem, et al.. Picosecond pulsed laser for microscale sample preparation. Materials Letters, 2015, 160, pp.589-591. 10.1016/j.matlet.2015.06.119 . hal-01514740

\section{HAL Id: hal-01514740 \\ https://hal.univ-lorraine.fr/hal-01514740}

Submitted on 7 Dec 2020

HAL is a multi-disciplinary open access archive for the deposit and dissemination of scientific research documents, whether they are published or not. The documents may come from teaching and research institutions in France or abroad, or from public or private research centers.
L'archive ouverte pluridisciplinaire HAL, est destinée au dépôt et à la diffusion de documents scientifiques de niveau recherche, publiés ou non, émanant des établissements d'enseignement et de recherche français ou étrangers, des laboratoires publics ou privés.

\section{(1) (1) $\$$}

Distributed under a Creative Commons Attribution - NonCommercial - NoDerivatives| 4.0 


\title{
Picosecond pulsed laser for microscale sample preparation
}

\author{
A. Guitton ${ }^{\text {a }}$, A. Irastorza-Landa ${ }^{\mathrm{a}, \mathrm{b}}$, R. Broennimann ${ }^{\mathrm{c}}$, D. Grolimund ${ }^{\mathrm{a}}$, S. Van Petegem ${ }^{\mathrm{a}}$, \\ H. Van Swygenhoven ${ }^{\mathrm{a}, \mathrm{b}, *}$ \\ a Paul Scherrer Institut, Swiss Light Source (SLS), CH-5232 Villigen PSI, Switzerland \\ b École Polytechnique Fédérale de Lausanne, NXMM-IMX-STI-EPFL, CH-1015 Lausanne, Switzerland \\ ${ }^{\mathrm{c}}$ EMPA Reliability Science and Technology Laboratory, CH-8600 Dübendorf, Switzerland
}

\section{A R T I C L E I N F O}

\section{Article history:}

Received 27 February 2015

Received in revised form

23 May 2015

Accepted 28 June 2015

Available online 2 July 2015

Keywords:

Defects

Laser processing

Metals and alloys

$\mathrm{X}$-ray techniques

Small scale mechanical testing

\section{Introduction}

Miniaturization of devices has made micromachining a necessity in materials science and engineering. Many small scale testing methods such as microcompression $[1,2]$, uniaxial tensile testing [3], microcantilever testing [4] or microshear testing [5] use Focused Ion Beam milling (FIBing) as the main technique to prepare samples. It is reported that $\mathrm{Ga}^{+}$ion implantation damages the material and can modify the microstructure (modification of dislocation structures, amorphization and/or formation of new intermetallic compounds) [2,6-9]. In order to get an adequate precision, low milling rate is needed. However for time constraints, it must be balanced with higher fluxes and energies, thus increasing the induced damage. Moreover, the milling rate depends strongly on the material and the crystallographic orientation $[10,11]$. Also, not all geometries are achievable by FIBing: for instance machining membranes (i.e. large, thin and deep areas

\footnotetext{
*Corresponding author at: École Polytechnique Fédérale de Lausanne, NXMMIMX-STI-EPFL, CH-1015 Lausanne, Switzerland.

E-mail addresses: antoine.guitton@psi.ch (A. Guitton), ainara.irastorza@psi.ch (A. Irastorza-Landa), rolf.broennimann@empa.ch (R. Broennimann), daniel.grolimund@psi.ch (D. Grolimund), steven.vanpetegem@psi.ch (S. Van Petegem), helena.vanswygenhoven@psi.ch (H. Van Swygenhoven).
}

with high aspect ratio) with good reproducibility and low roughness is time consuming and simply inconceivable by FIBing.

Here, we apply Ultra Short Pulsed (USP) laser ablation for micromachining samples. Laser ablation consists in ejecting matter from the sample by irradiation with short, energetic bursts of light. Because only photons are used, less damage is expected in comparison with FIBing. The duration of the pulses has an important effect on the introduction of damage into the material: shorter pulse durations reduce the heat diffusion leading to low damage, better surface quality, improved resolution and higher precision [12]. Most of the pulse energy goes indeed into excitation of electrons which ablates the surrounding material with a very small Heat Affected Zone (HAZ) [12-16]. In the case of picosecond pulses, craters of ablation are clean and molecular dynamics simulations predict that the HAZ exhibits a negligible concentration of defects such as vacancies and dislocations [17]. More details on the mechanisms of laser ablation can be found in the supplementary data.

The objective of this work is to machine out of a bulk material $10 \mu \mathrm{m}$ thin membranes with a diameter of a few hundreds of micrometers. Further imposed requirements are: (1) the roughness of the thinned area must be low, preferable a few hundreds of nanometers (2) a perfect control of the position of the membrane with high accuracy and reproducibility of the order of few micrometers; (3) the damage introduced during ablation must be minimized as much as possible. In this work the latter is verified by Laue x-ray microdiffraction. 
Table 1

Laser details and ablation parameters. (SHG: Second Harmonic Generation ; THG: Third Harmonic Generation).

\begin{tabular}{ll}
\hline Manufacturer & Lumera (now Coherent), Kaiserslautern, Germany \\
\hline Model & Super rapid with SHG, THG and first pulse killer \\
Maximal power at $355 \mathrm{~nm}$ & $\sim 4 \mathrm{~W}$ \\
Maximum repetition rate & $640 \mathrm{kHz}$ \\
Material removal method & Layered ablation \\
Process gas & Ambient air \\
Wavelength & $355 \mathrm{~nm}$ \\
Pulse duration & $10 \mathrm{ps}$ \\
Power & $50 \pm 2 \mathrm{~mW}$ \\
Frequency & $50 \mathrm{kHz}$ \\
Focal spot size & $\sim 5 \mu \mathrm{m}$ \\
\hline
\end{tabular}

\section{Thinning down by picosecond pulsed laser ablation}

Different materials purchased from Goodfellow were used: polycrystalline copper ("PolyCu") for optimizing the ablation parameters and monocrystalline copper ("MonoCu") for studying potential induced damage. In the case of MonoCu, ablation was made on several samples with the ablated surfaces parallel to $\sim\left(\begin{array}{lll}\overline{1} & 0 & 0\end{array}\right), \sim\left(\begin{array}{lll}0 & \overline{1} & 4\end{array}\right)$ and $\sim\left(\begin{array}{lll}2 & 2 & \overline{1}\end{array}\right)$.

MonoCu samples were cut by electrical discharge machining to a thickness of $100 \mu \mathrm{m}$. All sample surfaces were then electropolished to remove damage in the external layers. Finally, the samples were annealed at $1120 \mathrm{~K}$, followed by slow cooling to room temperature in about $20 \mathrm{~h}$.

For thinning down the sample laser pulses were directed by a galvano scanner in a cross hatch pattern towards the surface. To reduce the roughness, the distance between hatch lines was set exactly to 3 digitizing units $(\sim 4 \mu \mathrm{m})$ of the Digital-to-Analog Converter (DAC) for the galvano scanner to reduce aliasing effects. Additionally the hatch direction was constantly rotated by $60^{\circ}$. $\sim 300 \mathrm{~nm}$ per hatch is ablated with the parameters listed in Table 1. The first trials revealed that the perimeter of the membrane was more deeply thinned than the center, thus forming a trench. The depth of this trench increases with the amount of material ablated. Therefore to avoid trenching, the

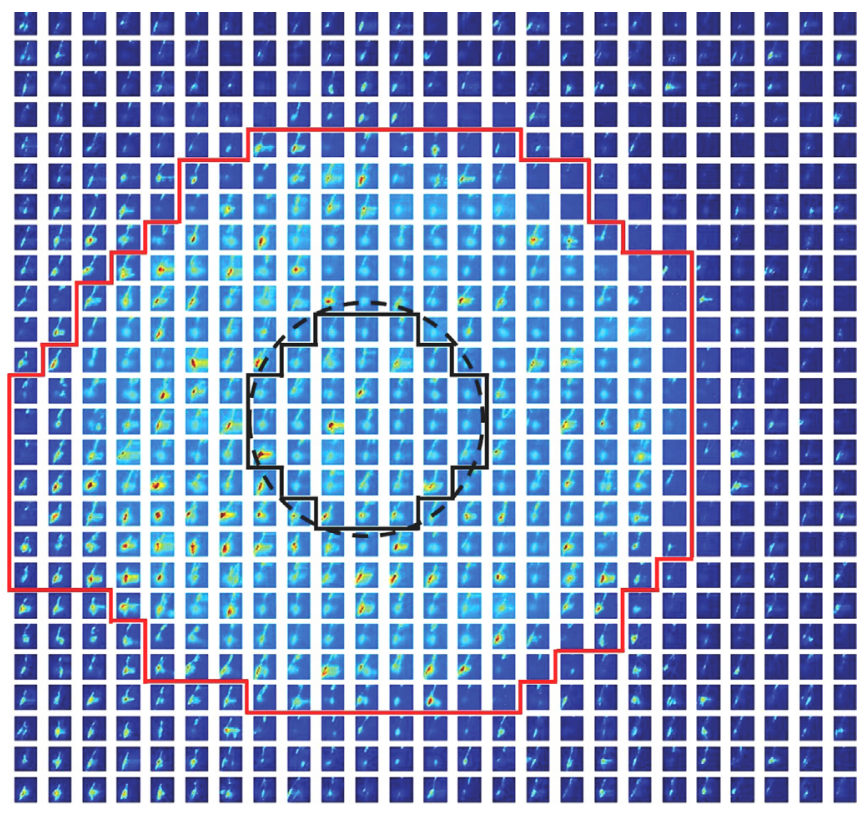

Fig. 2. 2D logarithmic scale diffraction map of the (131) reflection of the MonoCu $\sim\left(\begin{array}{l}1 \\ 0\end{array} 0\right)$ around the ablated zone. The pattern outside the red line are used to calculate the averaged values in the row "Out" of Table 2 and the ones inside the black line for the row "In" of Table 2. The area "In" corresponds to a circle with $120 \mu \mathrm{m}$ diameter. (For interpretation of the references to color in this figure legend, the reader is referred to the web version of this article.)

thinning process was done in a staircase concept as shown in Fig. 1a.

Fig. 1b shows a Scanning Electron Microscope (SEM) image of the membrane machined on PolyCu, and Fig. 1c provides the average membrane thicknesses measured by focal depth difference with an optical microscope (Olympus BX51). The root-meansquare (RMS) roughness of the thinned areas was determined with a white light interferometric microscope: an RMS roughness of about $500 \mathrm{~nm}$ was obtained for a length of $\sim 280 \mu \mathrm{m}$ per sample. Moreover, membranes are flat as illustrated in Fig. 1d by the 3D topography view of the thinned PolyCu sample.

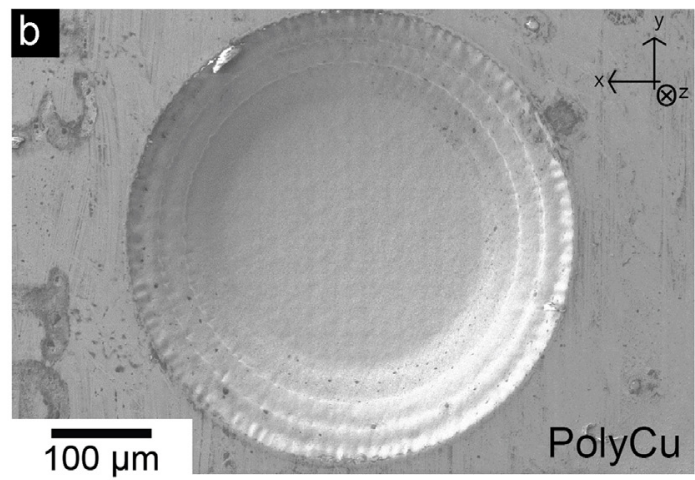

\begin{tabular}{|c|c|c|}
\hline C & & $\begin{array}{c}\text { Average thickness }(\mu \mathrm{m} \\
\pm 2 \mu \mathrm{m}\end{array}$ \\
\hline \multirow{4}{*}{$\mathrm{Cu}$} & Polycrystalline & 12.0 \\
\hline & $\sim(\overline{1} 00)$ & 10.9 \\
\hline & $\sim(0 \overline{1} 4)$ & 11.4 \\
\hline & $\sim(22 \overline{1})$ & 10.9 \\
\hline
\end{tabular}

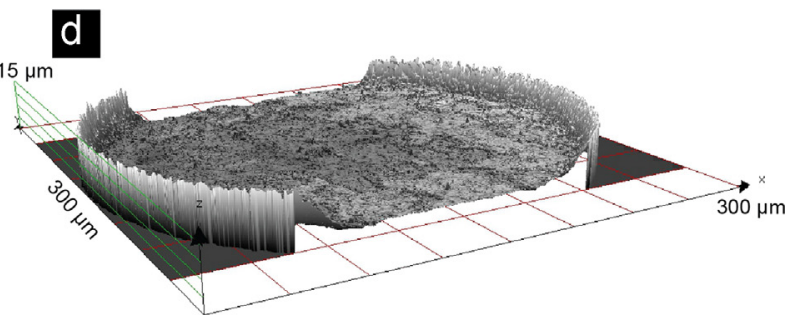

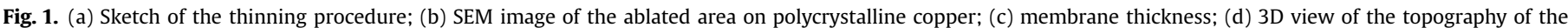
ablated area in polycrystalline copper. 
Table 2

Widths along $2 \theta$ and $\psi$ directions for each observed spot. $\bar{x}$ represents the mean value.

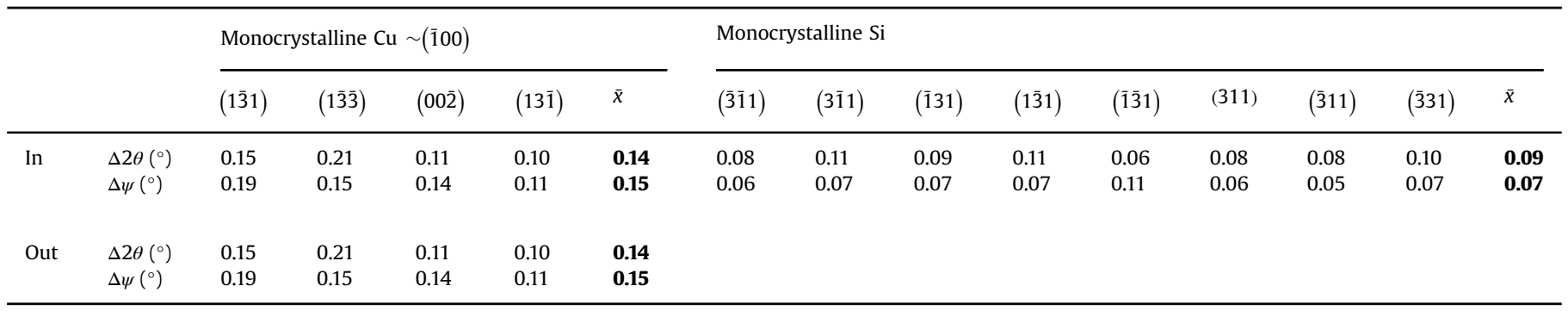

\section{Damage analysis by transmission $x$-ray Laue microdiffraction}

Laue microdiffraction is a powerful technique for evaluating defect microstructures: the spot broadening is sensitive to crystal orientation gradients and deviatoric strains, generally resulting from the density of Geometrical Necessary Dislocations (GND) in the probed volume $[8,18-20]$. The experiments are performed at the MicroXAS beamline of the Swiss Light Source. 2D spatially resolved diffraction patterns over the membranes are recorded with a white micro-beam in transmission mode. More details of this beamline and the experiment can be found in $[2,8]$ and in the supplementary data. In the following, diffraction results for MonoCu $\sim\left(\begin{array}{lll}1 & 0 & 0\end{array}\right)$ are given.

An area of $500 \times 500 \mu \mathrm{m}^{2}$ is scanned with a step size of $20 \mu \mathrm{m}$ along $x$ and $y$ axis over the ablated membrane (Fig. 2). The FullWidths at Half-Maximum (FWHM) along radial $(2 \theta)$ and azimuthal $(\psi)$ directions for each reflection in every patterns are calculated by fitting with a Pearson VII and their mean value can be found in Table 2. Comparison is made between patterns acquired inside and outside the ablated membrane. The averages $\overline{\Delta 2 \theta}$ and $\overline{\Delta \psi}$ are respectively $0.14^{\circ}$ and $0.15^{\circ}$ inside the membrane, and $0.18^{\circ}$ and $0.22^{\circ}$ outside the membrane which are even slightly higher than the former. These results are analog to those obtained in a damage-free $10 \mu \mathrm{m}$ thick monocrystalline Si (Table 2) acquired under the same diffraction conditions $\left(\overline{\Delta 2 \theta}=0.09^{\circ}\right.$ and $\left.\overline{\Delta \psi}=0.07\right)$. Similar results are obtained for other monocrystalline samples. Considering the challenging requirements, these results show that the preparation procedure based on picosecond pulsed laser ablation does not introduce important damage changing the shape of peak the profiles, as compared to samples prepared by FIBing $[8,9,20]$.

\section{Conclusions}

In summary, a novel strategy based on USP laser ablation is developed to machine large thin flat areas. Only few tens of minutes are needed to machine membranes, which is an enormous advantage compared to FIB. Laue microdiffraction demonstrates that the induced damage is minimal. Consequently, USP laser ablation has a high potential to replace FIB in many applications related to small scale mechanical testing and opens new possibilities for machining new geometries.

\section{Acknowledgments}

The authors thank Dr. Stéphane Portier (HOTLAB, PSI) for the roughness measurements. AG and HVS thank the European Research Council for the ERC-advanced Grant MULTIAX (339245).

\section{Appendix A. Supplementary information}

Supplementary data associated with this article can be found in the online version at http://dx.doi.org/10.1016/j.matlet.2015.06. 119.

\section{References}

[1] L. Thilly, R. Ghisleni, C. Swistak, J. Michler, In situ deformation of micro-objects as a tool to uncover the micro-mechanisms of the brittle-to-ductile transition in semiconductors: the case of indium antimonide, Philos. Mag. 92 (2012) 3315-3325.

[2] H. Van Swygenhoven, S. Van Petegem, The use of Laue microdiffraction to study small-scale plasticity, J. Miner. Met. Mater. Soc. 62 (2010) 36-43.

[3] C. Motz, Mechanical Testing with the Scanning Electron Microscope, (2012) 209-225.

[4] D.E. Armstrong, A.J. Wilkinson, S.G. Roberts, Measuring anisotropy in Young's modulus of copper using microcantilever testing, J. Mater. Res. 24 (2009) 32683276.

[5] J.K. Heyer, S. Brinckmann, J. Pfezing-Micklich, G. Eggeler, Microshear deformation of gold single crystals, Acta Mater. 62 (2013) 225-238.

[6] H. Bei, S. Shim, G. Pharr, E. George, Effects of pre-strain on the compressive stressstrain response of Mo-alloy single-crystal micropillars, Acta Mater. 56 (2008) 4762-4770.

[7] C.R. Hutchinson, R.E. Hackenberg, G.J. Shiflet, A comparison of EDS microanalysis in FIB-prepared and electropolished TEM thin foils, Ultramicroscopy 94 (2003) 37-48.

[8] R. Maaß, D. Grolimund, S. Van Petegem, M. Willimann, M. Jensen, H. Van Swygenhoven, T. Lehnert, M.A.M. Gijs, C. Volkert, E.T. Lilleodden, R. Schwaiger, Defect structure in micropillars using X-ray microdiffraction, Appl. Phys. Lett. 89 (2006) 151905.

[9] J. Zimmermann, H. Van Swygenhoven, C. Marichal, S. Van Petegem, C. Borca, B. Bartova, et al., Slip in directionally solidified Mo-alloy micropillars - Part I: nominally dislocation-free pillars, Acta Mater. 60 (2012) 4604-4613.

[10] B.W. Kempshall, S.M. Schwarz, B.I. Prenitzer, L.A. Giannuzzi, R.B. Irwin, F.A. Stevie, Ion channeling effects on the focused ion beam milling of Cu, J. Vac. Sci. Technol. B 19 (2001) 749-754.

[11] J.R. Phillips, D.P. Griffis, P.E. Russell, Channeling effects during focused-ion-beam micromachining of copper, J. Vac. Sci. Technol. A: Vac. Surf. Films 18 (2000) 1061-1065.

[12] S. Xiao, Picosecond Laser Ablation of Indium Tin Oxide Thin Film, Fakultät für Maschinenbau der Ruhr-Universität Bochum, 2012.

[13] B. Chichkov, C. Momma, S. Nolte, F. Von Alvensleben, A. Tünnermann, Femtosecond, picosecond and nanosecond laser ablation of solids, Appl. Phys. Lett. A. 63 (1996) 109-115.

[14] J. Jandeleit, G. Urbasch, H.D. Hoffmann, H.G. Treusch, E.W. Kreutz, Picosecond laser ablation of thin copper films, Appl. Phys. A 63 (1996) 117-121.

[15] J. Meijer, Laser beam machining (LBM), state of the art and new opportunities, J. Mater. Proces. Technol. 149 (2004) 2-17.

[16] C. Schäfer, H.M. Urbassek, Metal ablation by picosecond laser pulses: a hybrid simulation, Phys. Rev. B 66 (2002) 115404.

[17] D. Bouilly, D. Perez, L.J. Lewis, Damage in materials following ablation by ultrashort laser pulses: a molecular-dynamics study, Phys. Rev. B 76 (2007) 184119.

[18] R.I. Barabash, G.E. Ice, Microdiffraction analysis of hierarchical dislocation organization, in: K.H. Jürgen Buschow, Robert W. Cahn, Merton C. Flemings,

Bernhard Ilschner, Edward J. Kramer, Subhash Mahajan, Patrick Veyssière (Eds.), Encyclopedia of Materials: Science and Technology, Elsevier, Oxford, 2005, Second edition pp. 1-18.

[19] R.I. Barabash, G.E. Ice, J.W.L. Pang, Gradients of geometrically necessary dislocations from white beam microdiffraction, Mater. Sci. Eng. A 400-401 (2005) 125-131.

[20] J. Zimmermann, S. Van Petegem, H. Bei, D. Grolimund, E. George, H. Van Swygenhoven, Effects of focused ion beam milling and pre-straining on the microstructure of directionally solidified molybdenum pillars: a Laue diffraction analysis, Scr. Mater. 62 (2010) 746-749. 